\title{
EL GIMNASIO ECOLÓGICO LUMEN DE VALDESPINO DE SOMOZA
}

\author{
Santiago García Morilla \\ José Antonio Robles Tascón \\ jose.robles.tascon@unileon.es \\ Eduardo Álvarez del Palacio \\ eduardo.alvarez@unileon.es
}

Departamento de Educación Física y Deportiva Facultad de Ciencias de la Actividad Física y del

Deporte

Fecha de recepción: Noviembre 2015

Fecha de aceptación: Febrero 2016

http://dx.doi.org/10.15366/citius2016.9.1.004

\section{Resumen:}

El concepto de ecología y de utilización de materiales reciclables puede parecer que está de moda más que nunca en los tiempos actuales. Acostumbrados a la aplicación de las últimas tecnologías en los aparatos más avanzados al servicio del deporte, el rendimiento y a su vez al cuidado de la salud en sofisticados centros deportivos, encontramos en el ámbito rural, ubicado en plena maragatería, Valdespino de Somoza, una iniciativa cargada de sentido del cuidado con el entorno y de reutilización de materiales usados no sólo con un fin educativo y estético sino con un sentido totalmente práctico como fruto de una iniciativa que busca el homenaje de una especie en vías de extinción: el negrillo. Ésta realidad es fruto de varios años de trabajo y perfeccionamiento de un profesor de Educación Física.

Palabras claves: Gimnasio, ecológico, Valdespino de Somoza, negrillo, materiales reutilizables

\section{Title: GYM OF ECOLOGICAL LUMEN OF VALDESPINO SOMOZA}

\begin{abstract}
:
The concept of ecology and use of recyclable materials may appear to be more fashionable than ever in modern times. Accustomed to the application of the latest technologies in the most advanced sportsequipment service, performance and in turn
\end{abstract}


to health care in sophisticated sports centers, found in rural areas, in heart maragatería, Valdespino Somoza, an initiative laden sense of care with the environmentand recycling used not only an educational and aesthetic purpose but with a totally practical sense as a result of an initiative to the homage of a species endangered materials: the Field Elm. This reality is the result of several years of work and development of a passionate teacher of Physical Education

Key words: Gym, ecological, Valdespino Somoza, Ulmus Minor, reusable materials

\section{Introducción}

El trabajo que aquí se presenta sobre el Gimnasio ecológico de Valdespino de Somoza, localidad situada en la comarca de la Maragatería, en la provincia de León, pretende dar a conocer una original instalación para la práctica del ejercicio físico en contacto con el medio natural. La actividad física en la naturaleza es una de las características distintivas del propio ser humano en sus primeros niveles evolutivos, de modo que como afirma Karl Gross, "el ejercicio físico fue junto con la alimentación, uno de los principales medios de desarrollo al alcance de nuestros antepasados". Hoy día, en culturas alejadas de nuestra propia civilización, eso que nosotros etiquetamos, tal vez equivocadamente, como "tercer mundo", donde se sigue manteniendo una organización completamente tribal, nos seguimos encontrando con que el fortalecimiento físico y la alimentación siguen siendo parte fundamental de su modo de vida.

En nuestra sociedad se valora la actividad física en la naturaleza como una forma positiva de conocimiento y respeto de nuestro entorno natural, de mantenimiento de las capacidades físicas, y de ocupación del tiempo libre. También en las manifestaciones deportivas del más alto nivel, se proclama el respeto al medio natural. Un ejemplo evidente de ello lo encontramos en la Carta Olímpica, que en su capítulo I, titulado El Movimiento Olímpico y su actividad, en el apartado 2. Misión y función del COI, punto 13, se recoge la necesidad de "estimular y apoyar una actitud responsable en los problemas del medio ambiente, promover el concepto de desarrollo durable en el deporte y exigir que los Juegos Olímpicos se celebren en consecuencia", completándose este planteamiento en el punto 15, donde se afirma que se debe de "estimular y apoyar las iniciativas que asocian el deporte con la cultura y la formación". El apartado 5, Solidaridad Olímpica, en el punto 7, se refiere a la posibilidad de "construir, en caso de necesidad, instalaciones deportivas sencillas, funcionales y económicas en cooperación con los organismos nacionales e internacionales".

Si nos remontamos a los antecedentes históricos más próximos que fundamentan nuestro trabajo, hemos de situarnos en el siglo XVIII, el conocido en 
la Historia de la Educación como "el siglo educador" por la gran cantidad de filósofos y pedagogos que se interesaron por el hecho educativo, y entre ellos merece una mención especial el filósofo ginebrino Jean Jacques Rousseau, cuyo pensamiento original se centra en la consideración del hombre como naturalmente bueno y generoso, siendo la sociedad la que lo hace malo y egoísta; sería necesario, pues, devolverlo a su estado natural.

En 1762, en su ensayo l'Emile, revela los principios de la educación ideal: la naturaleza es la mejor guía del educador. En consecuencia el cuerpo, primer instrumento de nuestra consciencia, necesita de toda nuestra atención. El niño debe de ejercitarse, de moverse, de descubrir a la vez sus sentidos y su eficacia. La educación natural de Rousseau abrió la puerta a lo que posteriormente fue considerado como los métodos utilitarios de la Educación Física.

El Filósofo ginebrino fue el primero en propagar la necesidad de una gimnasia infantil, de modo que los niños fueran trasladados a la naturaleza para poder correr, saltar y trepar a su libre albedrío. Su programa educativo estaba fundamentado en el agir, es decir el obrar. La escuela no debe de limitarse a trasmitir el saber, sino que debe de enseñar a actuar de forma acertada y decidida. Recomienda Rousseau toda una serie de tareas física en contacto con la naturaleza y aprovechando sus propios medios: la trepa de árboles, el levantamiento pesos, el lanzamiento de piedras, los ejercicios de equilibrio y los hábitos a la superación de obstáculos y al peligro, siendo famosa su frase referida al niño Emilio: "si pudiera enseñarle a volar, haría de él un águila".

Buen número de maestros, pedagogos y filósofos de la época fueron estimulados por la obra de Rousseau, entre ellos cabe destacar a Juan Enrique Pestalozzi, que vislumbró la necesidad de un adecuado desarrollo físico como parte importante de una educación general que "facilitase la adaptación de la persona y el desarrollo de su capacidad mental". Juan Bassedow, Friedich Luwig Jhan, y Guth-Musth, se inscribirían también en la amplia nómina de seguidores de Rousseau.

De este modo, el método natural puede considerarse como una reacción contra la artificiosidad y el espíritu analítico de la gimnasia sueca de la época, en palabras del propio George Hébert, su principal inspirador y entusiasta seguidor de Rousseau, "insuficientemente conocida, mal comprendida e incorrectamente aplicada". El método natural, sería pues, en sus propias palabras, "la codificación, la adaptación y la gradación de los procedimientos y medios empleados por los seres vivientes en estado natural para adquirir su desarrollo integral”. 
La principal fuente de inspiración de Hébert fue la observación de las costumbres de los pueblos primitivos y su influencia sobre la formación física y la salud de sus integrantes. Asimismo reconoce la influencia que sobre su obra ejercieron el propio Filósofo ginebrino, Francisco Amorós y George Demeny.

Al español Amorós y a su compatriota George Demeny se refiere Hébert como "dos grandes maestros que destacan entre todos los demás porque han buscado los mejores medios para construir la educación física de la juventud y de estructurar una doctrina. Ellos han tratado el problema en su conjunto y desde una triple perspectiva: fisica, viril y moral".

Afirma Hébert, que su Método Natural, también conocido como Hébertism, pretende ser una acción metódica, progresiva y continua, desde la infancia a la edad adulta, teniendo por objeto asegurar un desarrollo físico integral, acrecentar la resistencia orgánica, mejorar la marcha, la carrera y el salto por medio de ejercicios variados realizados en la propia naturaleza y aprovechando los medios que ella misma nos brinda.

La sesión de ejercicio físico en la naturaleza, definida por nuestro autor como "recorridos físicos en el medio natural", pueden realizarse de dos formas: una, realizando un itinerario andando y corriendo, superando todos los obstáculos naturales que la propia naturaleza nos brinda; otra se realizaría sobre un espacio restringido -plateau (espacio) de trabajo-, especialmente apropiado y acondicionado con material para la ejecución de un trabajo físico de acondicionamiento físico general y específico. El Gimnasio objeto de nuestro estudio se correspondería con este tipo de instalación.

Para George Hébert, el desarrollo físico no lo es todo, pues es inseparable de una cultura viril que desarrolle le energía y todas las demás cualidades de acción y de una cultura moral con la exaltación de los sentimientos de nobleza de la persona. Fortalecer los órganos y los músculos no constituye más que una parte de la educación general, pues dicho fortalecimiento hay que colocarlo al servicio del bien social.

Así pues, la Educación Física es para el padre de la gimnasia natural "una cuestión de orden pedagógico y no fisiológico, y todavía menos médico, pues necesita de un conocimiento profundo del niño y del adolescente, que sólo están en condición de poseer los maestros, es por ello que debe de ser una obra escolar".

La clasificación de los ejercicios físicos que Hébert realiza, en base al nivel de esfuerzo físico exigido y al efecto producido en el cuerpo humano, se ordenarían 
en diez grupos fundamentales: la marcha, la carrera, el salto, la cuadrupedia, la trepa, el equilibrio, el lanzamiento, el levantamiento de pesos, la lucha, y la natación.

La obra de Hébert es un canto a la vida, al aire libre, al trabajo en plena naturaleza, al desnudo -dentro de lo que la decencia permite-, y a los ejercicios físicos naturales y utilitarios. La contribución de Hébert supera los límites de la actividad física como práctica conveniente y saludable, para instalarse en una filosofía o forma de vivir en contacto con la naturaleza.

Es obligado resaltar el hecho de que Hébert, en su obra Músculo y belleza plástica, publicada en Paris en 1921, defendió los beneficios del ejercicio físico para las mujeres, de modo que así lo expresa: “... siguiendo mi método natural de desarrollo sintético fisico, energético y moral, las mujeres pueden desarrollar confianza en sí mismas, fuerza de voluntad y capacidad atlética tan bien como sus contrapartes masculinas".

También Pierre de Coubertin, preocupado por la sobrecarga de los contenidos "intelectuales" de los programas escolares de los centros docentes franceses de su época afirmaba en Remedio contra el Surmenage, (1889, p.51), que producían

"embotamiento intelectual y debilidad moral", por lo que en sus "proyectos de reforma total de los programas de enseñanza", proponía "el establecimiento de liceos en el campo". "Poniendo el ejercicio físico como contrapeso a la fatiga intelectual, ...intentando que en la educación entraran, mediante el deporte, nuevos principios de disciplina y responsabilidad" (Coubertin, 1888, p. 249).

Así recordaba en una conferencia celebrada el 29 de mayo de 1888 en el Congreso Anual de Economía Social, con el título "Le remede au surmenage et la transformation des Lycées de París":

"El director de una institución me hacía los honores de una visita a un patio aireado en el que se habían plantado una decena de árboles; alrededor de 30 niños se dedicaban alli a hacer pequeños movimientos liliputienses y mil niñerías, cuatro o cinco estaban parados en las esquinas; varios se paseaban gravemente; ... otros se divertían ...."(Coubertin, 1889, p. 51).

En la misma conferencia afirmaba:

"En el colegio Monge los paseos de los jueves se hacen por el campo... es preciso que nuestros escolares encuentren ... lo que les falta en Paris, campos para jugar 
y juegos organizados.." se trata, por lo tanto, de crear parques escolares con vastas praderas divididas y mantenidas de acuerdo con las necesidades de estos juegos,...Los alumnos de las distintas escuelas irían alternativamente a pasar alli la tarde, y así, en pleno campo, cabría, proporcionarles los placeres más variados; paseos, carreras, búsqueda de tesoro críquet, tenis, etc...."(Ibídem: p. 56).

Cualquiera que fuese la importancia que doy al deporte en sí mismo y por sí mismo, confieso que lo considero sobre todo un medio y que, coincidiendo en esto con todos los maestros ingleses y con más de un maestro francés, espero de él tres cosas: la primera, que restablezca en nuestras jóvenes generaciones el equilibro roto desde hace mucho tiempo entre el cuerpo y el espíritu, que les dé no tanto una fuerza momentánea cuanto una salud duradera y una prolongación de la juventud que le permite al hombre dejar tras de sí una obra sólida y acabada. La segunda que, en la edad crítica, aleje tentaciones contra las que nada en nuestro régimen actual, opera eficazmente; que proporcione un ámbito de entusiasmo, que procure un sano cansancio, que apacigüe los sentidos y la imaginación. Pero espero también, una tercera cosa...una integración social voluntaria...sentido común y carácter... (Ibidem, p. 58).

En tiempos más recientes, existen propuestas novedosas que han intentado acercar la práctica física en la naturaleza a los ciudadanos, como por ejemplo los famosos circuitos VITA, patrocinados por la compañía suiza de seguros del mismo nombre, que confeccionó una serie de recorridos en la naturaleza con diferentes estaciones en las que se realizaban ejercicios de acondicionamiento físico general, graduados en intensidad y número de repeticiones en función del diferente nivel de los participantes. En nuestro país se hicieron famosos este tipo de circuitos naturales por ser patrocinados por conocidas firmas comerciales, como Cola-Cao, Coca-Cola, etc.

Entendemos, y este es el motivo de nuestro trabajo, que esta instalación de Valdespino supone una aportación interesante de su autor a la divulgación de la práctica física en el medio natural, a la vez que conlleva el uso de materiales reciclados que contribuyen a la sostenibilidad de nuestro medio ambiente.

\section{Análisis del Gimnasio Lumen}

Esta idea que como vemos no es completamente original en el tiempo ya que existen diferentes iniciativas llevadas a cabo por educadores y pedagogos a lo largo de los últimos siglos en diferentes puntos de Europa, sí que lo es en España, al menos desde el punto de vista del autor maragato. Para ello confluyen tres objetivos fundamentales que conforman la esencia de esta instalación: por un lado la finalidad motriz, es decir el trabajo de los diferentes segmentos del cuerpo como medio de mantenimiento físico, lo que veremos a continuación en la parte final del 
presente estudio. Por otro el pedagógico, como medio de enseñanza de una serie de valores culturales, y en tercer lugar el carácter ecológico que rodea todo el gimnasio. Éste último, como dice el autor, es un homenaje al negrillo, a esta especie autóctona tan habitual en la zona y que fue atacada por la grafiosis, lo que ha propiciado la desaparición de la mayoría de sus ejemplares.

La clave pedagógica que une deporte y educación ya aparece recogida en la Carta Olímpica, que en su apartado de Principios Fundamentales del Olimpismo, punto 2, afirma que "El objetivo del Olimpismo es poner siempre el deporte al servicio del desarrollo armónico del hombre, con el fin de favorecer el establecimiento de una sociedad pacífica y comprometida con el mantenimiento de la dignidad humana". Se complementa este principio con el recogido en el punto 4, "La práctica deportiva es un derecho humano. Toda persona debe tener la posibilidad de practicar deporte sin discriminación de ningún tipo y dentro del espíritu olimpico, que exige comprensión mutua, solidaridad y espiritu de amistad $y$ de fair play. La organización, administración y gestión del deporte deben ser controladas por organizaciones deportivas independientes".

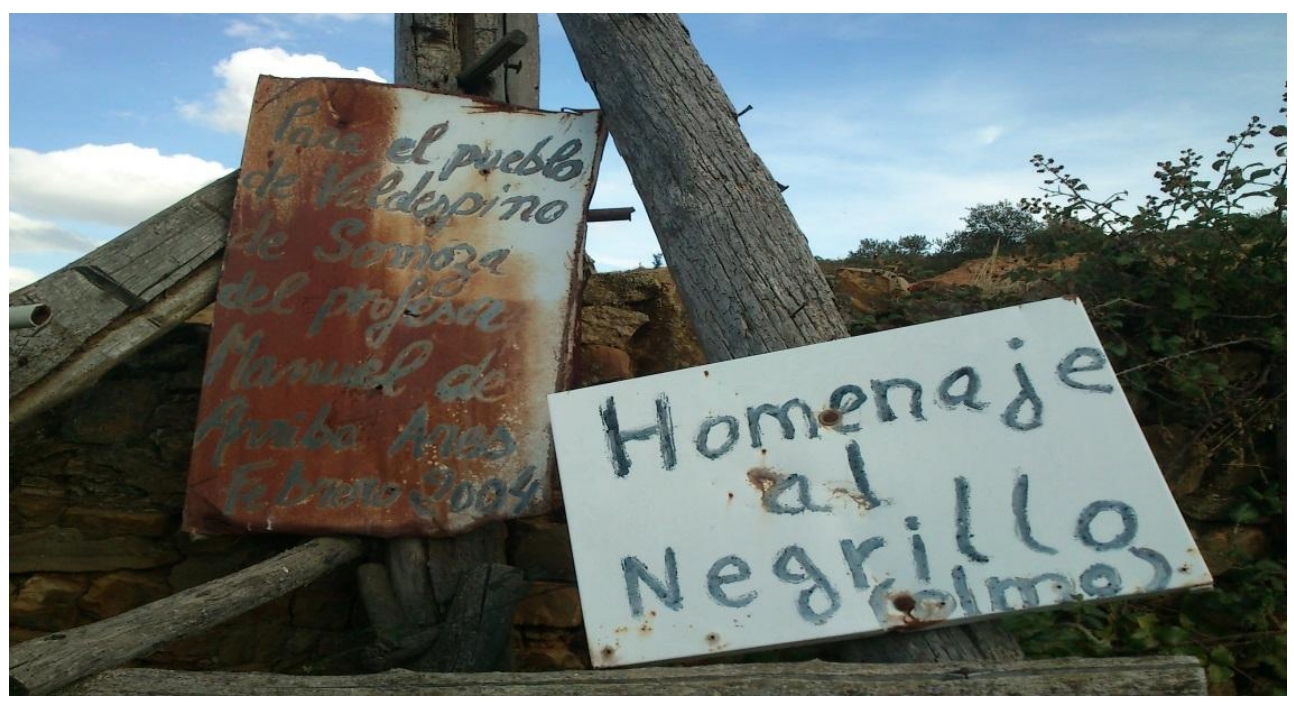

Foto 1. Imagen del gimnasio ecológico Lumen de Valdespino de Somoza.

Este hecho supone un acontecimiento que marca el futuro proyecto de la creación de la instalación y que no puede dejarse pasar por alto ya que marca su identidad y es un motivo para rendirle tan singular homenaje. Efectivamente, la elección de la madera de negrillo no ha sido una casualidad. Por un lado, el 
negrillo, nombre con el que se le conoce popularmente al olmo (ulmus minor $\mathrm{u}$ olmo de Locke), es un árbol grueso, alto -pueden llegar a alcanzar una altura de hasta 40 m.-, relativamente sencillo de trabajar y muy resistente, característica imprescindible en aparatos de tracción y fuerza que son los que componen mayoritariamente los gimnasios. Su madera ha sido siempre muy codiciada por los ebanistas, pero más aún por los habitantes de la zona quienes la elegían para la fabricación de puertas, vigas y mesas. Especialmente caracterizada por su dureza y resistencia a la intemperie, pero también por su belleza estética, ya que su madera posee el corazón marrón claro o pardo rojizo, con anillos de crecimiento muy marcados y textura algo gruesa, lo que le confiere una belleza poco común.

Probablemente una de las características más importantes que ofrece este árbol caducifolio es la resistencia a la humedad, cuestión muy a tener en cuenta en instalaciones de este tipo que se encuentran al aire libre. La tendencia general de la madera frente a los agentes externos, principalmente el sol y el agua, así como las amplias variaciones térmicas es a la putrefacción, sobre todo cuando se encuentra húmeda, por lo que en tiempos pasados era muy habitual su uso para construcciones navales e inclusive conducciones de agua. Esta cuestión es paliada por la elección del negrillo, máxime cuando la ubicación de la maragatería está caracterizada por veranos muy calurosos e inviernos muy fríos, por lo tanto, con gran oscilación térmica entre el día y la noche.
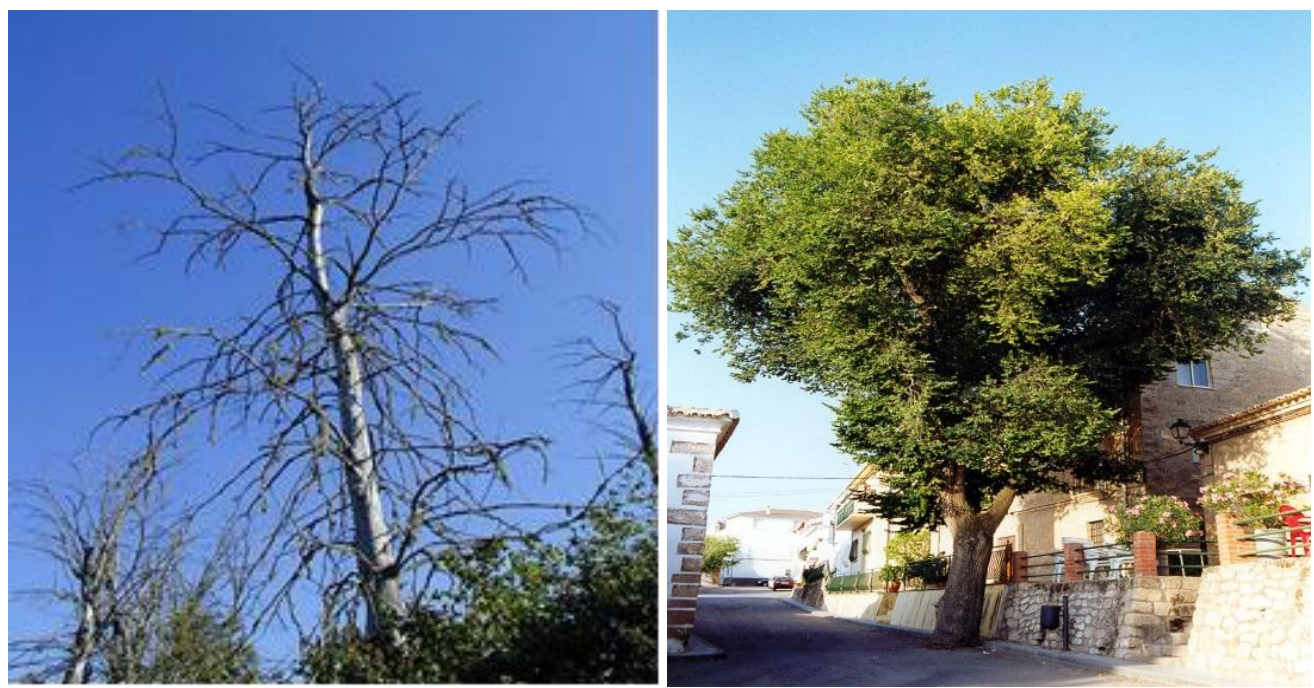

Foto 2. Diferencia entre un ejemplar de negrillo afectado por la grafiosis y un ejemplar sano.

Citius, Altius, Fortius Volumen 9 ne 1 Mayo, 2016. ISHN. 2340-9886.

http://dx.doi.org/10.15366/eitius2016.9.1 
La otra característica fundamental para su utilización en la instalación era su abundancia. Como en muchos otros lugares de la meseta castellana, fue una de las especies arbóreas más habituales, encontrándose en las inmediaciones de las poblaciones. Además, es una de las especies más sencillas de trasplantar y su semilla nace y se desarrolla con facilidad. La cuestión es que el negrillo era una especie muy abundante en la zona de la maragatería hasta sufrir la grafiosis, lo que provocó su casi total desaparición.

Esta enfermedad está producida por un hongo, concretamente de la familia de los ofiostomatáceas (Ceratocystis ulmi), que obstruye los vasos y hace que se sequen las hojas para finalmente terminar secando el tronco. Esta enfermedad ha desolado la mayoría de los ejemplares de la zona castellana, pero al tratarse de una plaga mundial, no sólo ha afectado a ejemplares de la Península Ibérica sino gran parte de Europa, Asia, Estados Unidos, Canadá y Nueva Zelanda. La propagación de la enfermedad se produce a través de un escarabajo (género Scolytus) que transporta en su cuerpo esporas del hongo a ejemplares sanos desde ejemplares ya afectados por ella. La plaga ha sido de tal magnitud que se calcula que en el año 1986 el 82\% de los olmedos españoles ya estaban infectados y diez años más tarde, en 1996, la enfermedad había acabado con más de la mitad de los olmos de Europa y Estados Unidos, a pesar de los esfuerzos en combatirla con insecticidas, podas estratégicas, o incluso la eliminación directa por medio de la quema de los ejemplares afectados. Sin embargo todo ha sido fallido y ha supuesto un verdadero drama desde el punto de vista del ecosistema. Este es el motivo por el que su autor utilizó para la construcción de los diferentes aparatos madera de negrillo afectada por la enfermedad, tratándose en su mayoría de leños de entre metro y metro y medio de longitud.

Teniendo en cuenta esta problemática no es difícil entender el porqué de este homenaje al negrillo del profesor Ares. Cada vez es más habitual esta relación entre actividad física y ecología. Los amantes al deporte tienen en el medio ambiente un escenario único donde practicar deporte, de hecho, muchas de éstas prácticas deportivas es indispensable realizarlas en el medio natural para que se puedan llevar a cabo, como es el caso del esquí, la bicicleta de montaña, la escalada, la vela, deportes de aventura, motocross, trial, carreras de orientación, etc. Este sentimiento de protección a la naturaleza es habitual entre deportistas y el cuidado y respeto de este medio ha pasado de ser algo anecdótico entre unos pocos a formar parte de un valor fundamental y añadido del deporte. Simplemente, sin el cuidado del medio ambiente no existirían estos deportes.

Si nos referimos a valores, en la actualidad este carácter ecológico es un sentimiento más en alza que nunca y está íntimamente ligado a cuestiones 
pedagógicas. Conscientes de que los recursos son limitados, el reciclaje y la utilización de materiales no sólo biodegradables sino también reutilizables forma parte de las actividades educativas en el contexto escolar. Esta conciencia ha cobrado fuerza en los países desarrollados en los últimos cincuenta años, sin embargo en España es en los últimos veinte cuando más hemos notado este cambio de actitud. Priorizar unos materiales sobre otros y conocer el origen, finalidad y proceso de reutilización forma parte del carácter pedagógico que el autor de la instalación ha pretendido. Estos viejos materiales han servido para crear, complejos en unos casos y sencillos en otros, mecanismos con una utilidad patente para la salud. El gimnasio ecológico Lumen sirve como modelo de sostenibilidad para educadores y escolares que visitan frecuentemente la instalación con la consiguiente sorpresa y admiración que provoca.

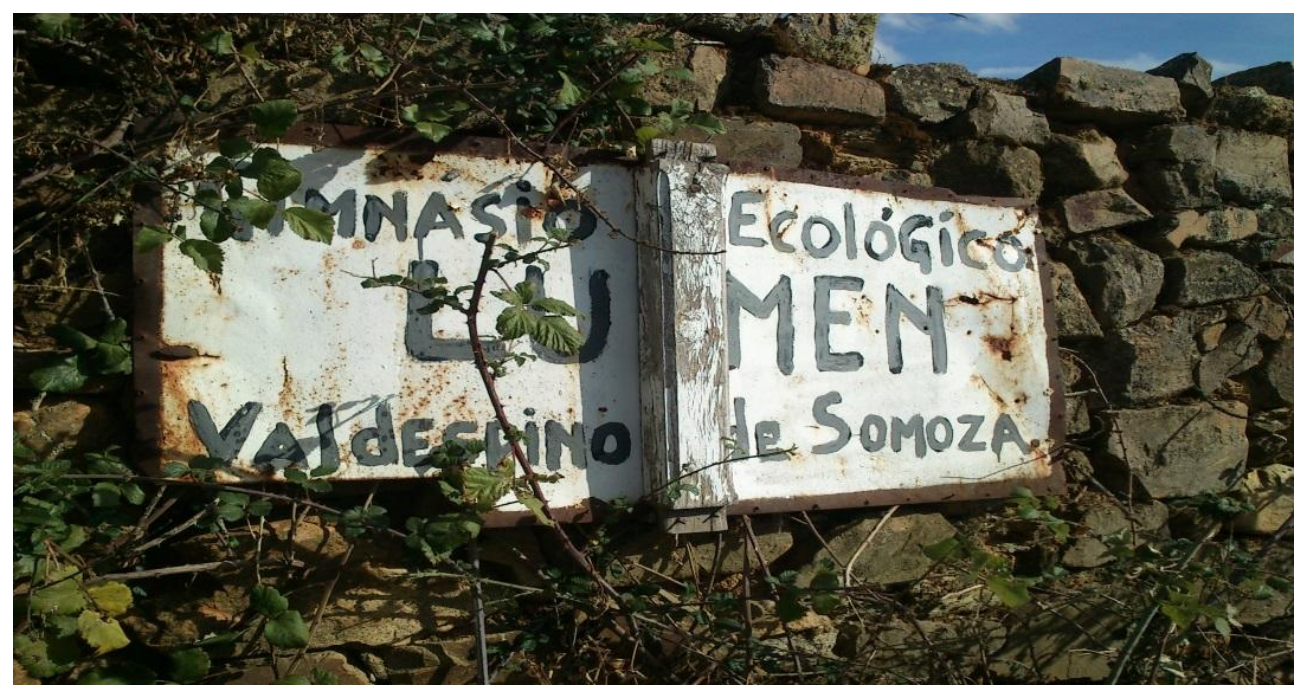

Foto 3. Carteles ubicados el gimnasio.

En plena maragatería y colindando con la conocida población de Val de San Lorenzo, encontramos la instalación deportiva, de ocio y recreo que tiene por nombre Gimnasio Ecológico Lumen. Como ya hemos informado, se encuentra en la localidad de Valdespino de Somoza, exactamente en el paraje conocido como Piqueras, perteneciente al barrio de abajo. Hay que señalar que a pesar de la reducida población que habita durante todo el año, el pueblo consta de tres barrios (barrio del Monte, barrio de Arriba y barrio de Abajo), señal inequívoca de tiempos pasados con una población mucho mayor. 
La instalación es relativamente reciente, ya que el año 2004 es el comienzo de su construcción. El proceso hasta llegar a la conformación actual ha sido lento y laborioso como el propio autor señala. En la actualidad consta de unos setenta aparatos, muchos de ellos repetidos pero mejorados. Podemos decir que la instalación ha llegado a su plenitud en cuanto a la extensión, puesto que el objetivo es mantener aparatos que por su construcción y finalidad, sufren un deterioro normal motivado por su uso.

Las herramientas utilizadas para su construcción no han sido muy numerosas, pero sí caracterizadas por su sencillez; apenas unas sierras, hachas, martillos... así lo proclama su autor en un cartel situado en la instalación, y como homenaje a sus vecinos:

"Este gimnasio ecológico "Lumen" es mi modesta aportación a mi pueblo Valdespino de Somoza de forma altruista. Realicé esta obra de manera totalmente artesanal: martillo, hacha, barreños, sierra y pico, fueron mis herramientas, además de mis humildes conocimientos como profesor de Educación Física.

Evidentemente, este trabajo se basa en el reciclaje, el "alma mater" es el olmo (negrillo) arrasado por la grafiosis.

También usé viejas vigas desechadas de casas en reparación. Tuve la colaboración ciudadana en cuanto a conseguir elementos que luego utilice." (Manuel de Arriba Ares. Junio 2002)

En cuanto a su construcción ha sido completamente artesanal. Podemos decir que el gimnasio ha estado dividido en dos importantes etapas en cuanto a su construcción. Por un lado la fase inicial, de creación de la instalación con los primeros aparatos y que como es lógico son más sencillos y rudimentarios. Los materiales utilizados en esta primera fase, además de la madera de negrillo, son cuerdas utilizadas como cabrestante, piedras para pesos, y uniones y ensamblajes simples. La segunda fase, que podemos denominar como de mantenimiento, perfección y creación de nuevos aparatos, es la imagen que hoy puede verse de la instalación, y básicamente ha consistido en la corrección de fallos en la construcción y el perfeccionamiento de mecanismos, así como la sustitución de primitivas piezas por otras con más consistencia, como por ejemplo cadenas por las cuerdas iniciales como sistema de trasmisión, sistemas de poleas más complejos, uniones y engranajes más perfeccionados y como indica el autor, la repetición de algunos aparatos con su diseño mejorado, para dotarlos de una mayor consistencia. 


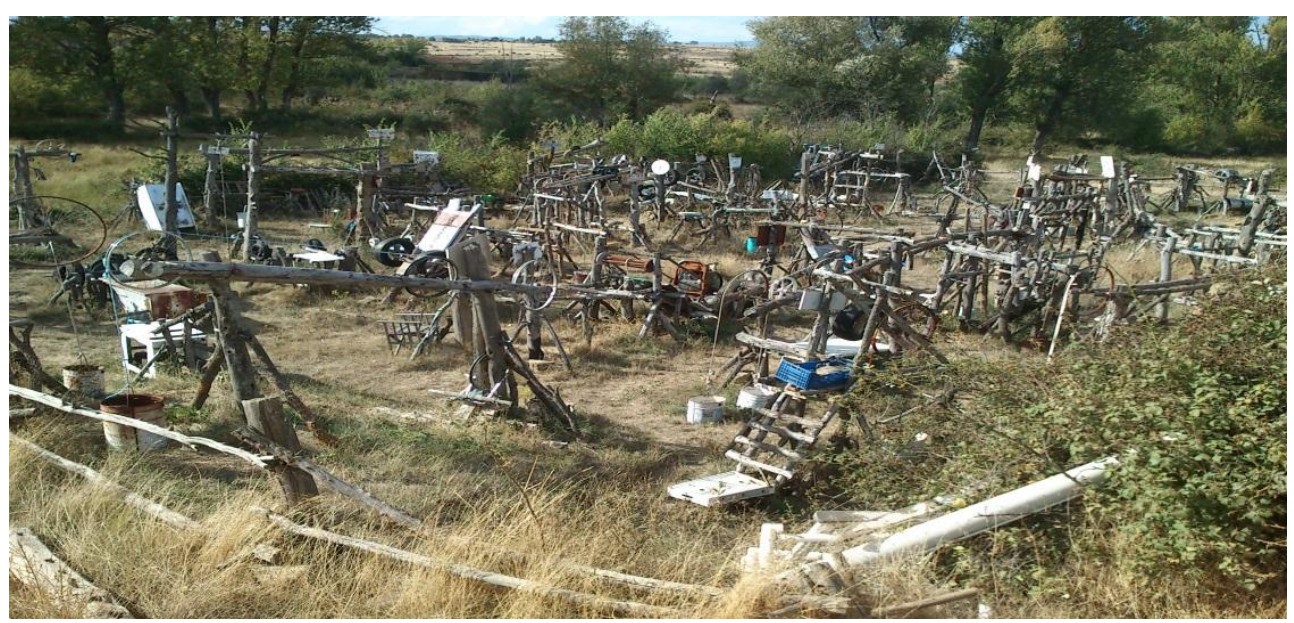

Foto 4. Vista panorámica de la instalación de Valdespino

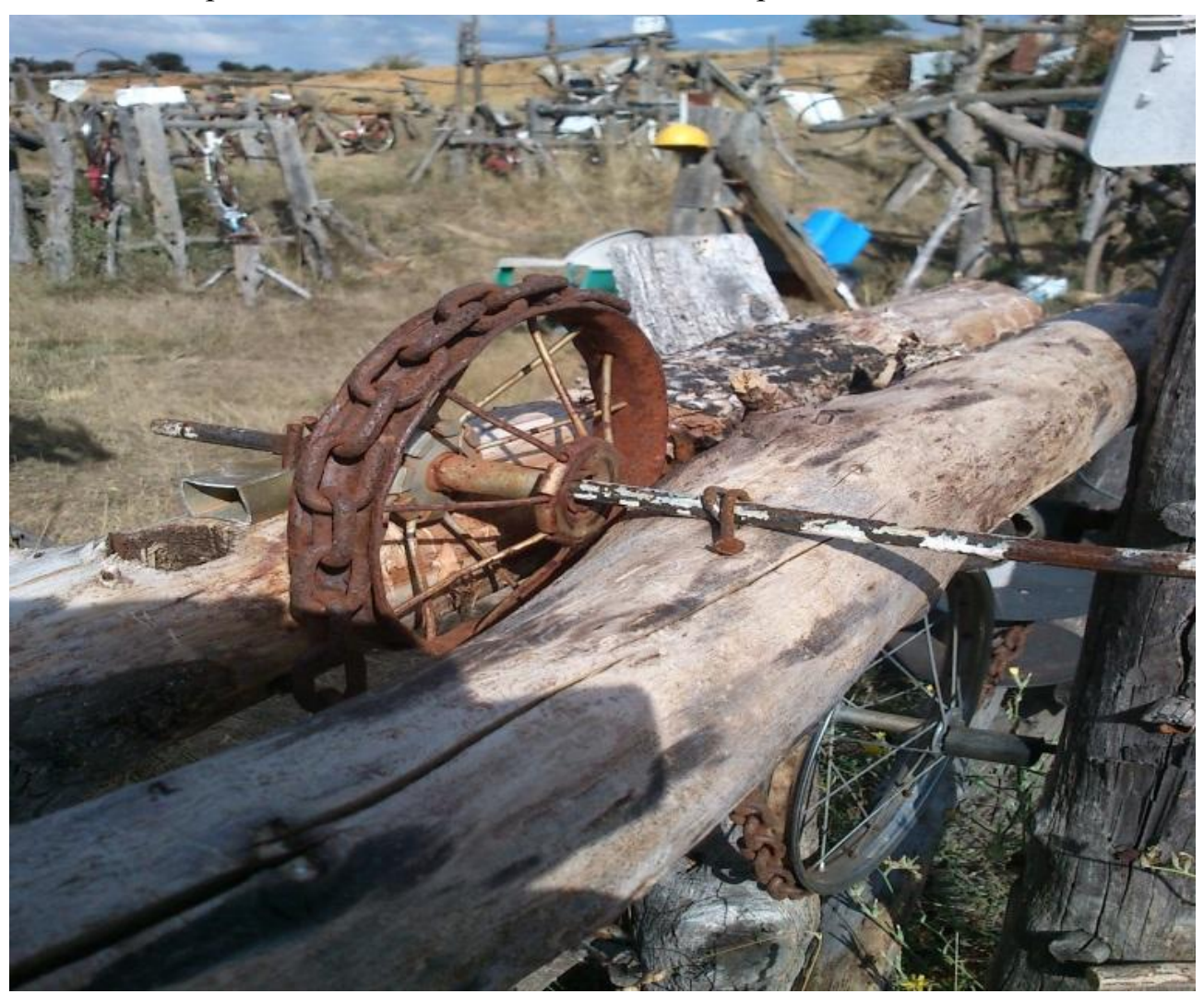

Foto 5. Polea perfeccionada con cadena y eje metálico

Citius, Altius, Fortius Volumen 9 ne 1 Mayo, 2016. ISHN. 2340-9886.

http://dx.doi.org/10.15366/citius2016.9.1 
Podemos encontrar una perfecta conjunción entre materiales como poleas conformadas por ruedas de bicicleta de tamaños diferentes, utilización de bombos de lavadoras para funciones similares, neveras para ser utilizadas en forma de banco, con el fin de poder realizar ejercicios de press banca, calderos para ser utilizados como contenedor para introducir pesos (generalmente piedras), utilización de ruedas como pesos o como parte de engranajes junto con ruedas o bloques para barra en peso libre.

El carácter educativo de la instalación es patente en cada rincón. Su autor ha dotado a todo el gimnasio y en particular cada aparato de una serie de carteles que de manera muy pedagógica instruyen a los usuarios no solamente para responder a la pregunta "para qué sirve este aparato" sino recomendaciones de cómo se ha de ejecutar correctamente el movimiento. Se encuentran a la vista de cada uno de ellos y con un sencillo dibujo indica los principales grupos musculares que se trabajan así como la acción muscular (flexores, extensores...) e inclusive algunas recomendaciones.

Estas recomendaciones hacen referencia de un modo muy pedagógico también a cuestiones que tienen que ver más con el cuidado del entorno y la instalación como se puede leer a continuación:

Han existido varias dificultades dentro del proceso de construcción. Por un lado el resultado de la conjunción de la ecología y la eficiencia para la finalidad que ha sido construido. El perfecto funcionamiento de los aparatos es un hecho patente. La diferencia con otro tipo de iniciativas es que en este caso no se ha buscado un complejo para ser admirado, sino una instalación útil y eficaz para los vecinos y visitantes. Se construyó para ser utilizada, para lograr resultados y por ello el funcionamiento ha de ser óptimo. Esto mismo guarda relación con otra de las dificultades principales, que es su mantenimiento. Cualquier aparato diseñado para estos fines sufre las penalidades y desajustes propios del uso, máxime si éste requiere del uso de pesos. Una construcción de este tipo en madera resulta muy delicada y de un mantenimiento continuo. La sustitución de unas maderas por otras, de cuerdas o cables por cadenas, y de piedras por otros pesos como bloques hay que hacerla a menudo. Sin duda, son las uniones y rodamientos simples los que requieren de más atención, siendo necesaria su continua supervisión, más aún al tratarse de aparatos que se encuentran al aire libre, sujetos a importantes oscilaciones térmicas que varían entre los 35 grados positivos en época estival y los 5-6 grados bajo cero de las frías noches del invierno leonés. Todo ello incluyendo la acción directa del sol, las lluvias propias de la primavera y el otoño, lo que afecta directamente a la madera a pesar de ser negrillo y tener una amplia 
tolerancia a la humedad. Por todo ello, el mantenimiento de una instalación tan grande, con unos 70 aparatos, es muy exigente para una sola persona.
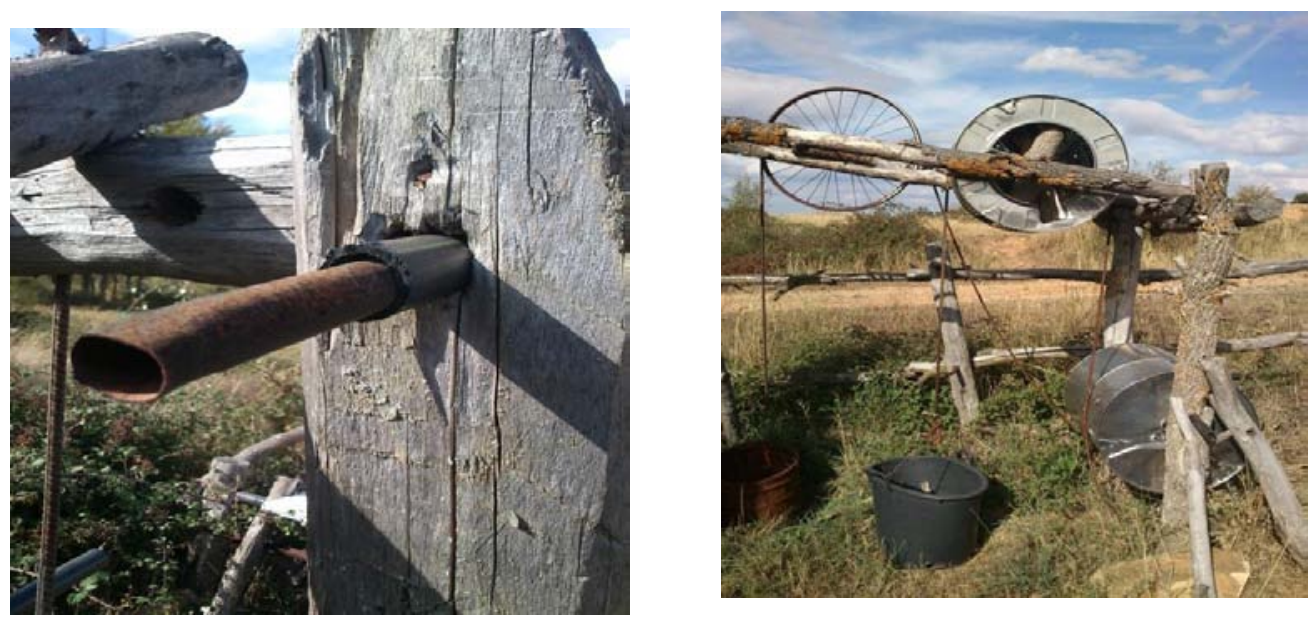

Foto 6. Detalle de uno de los puntos de sujeción. Mezcla de materiales con goma recubriendo a una barra de metal
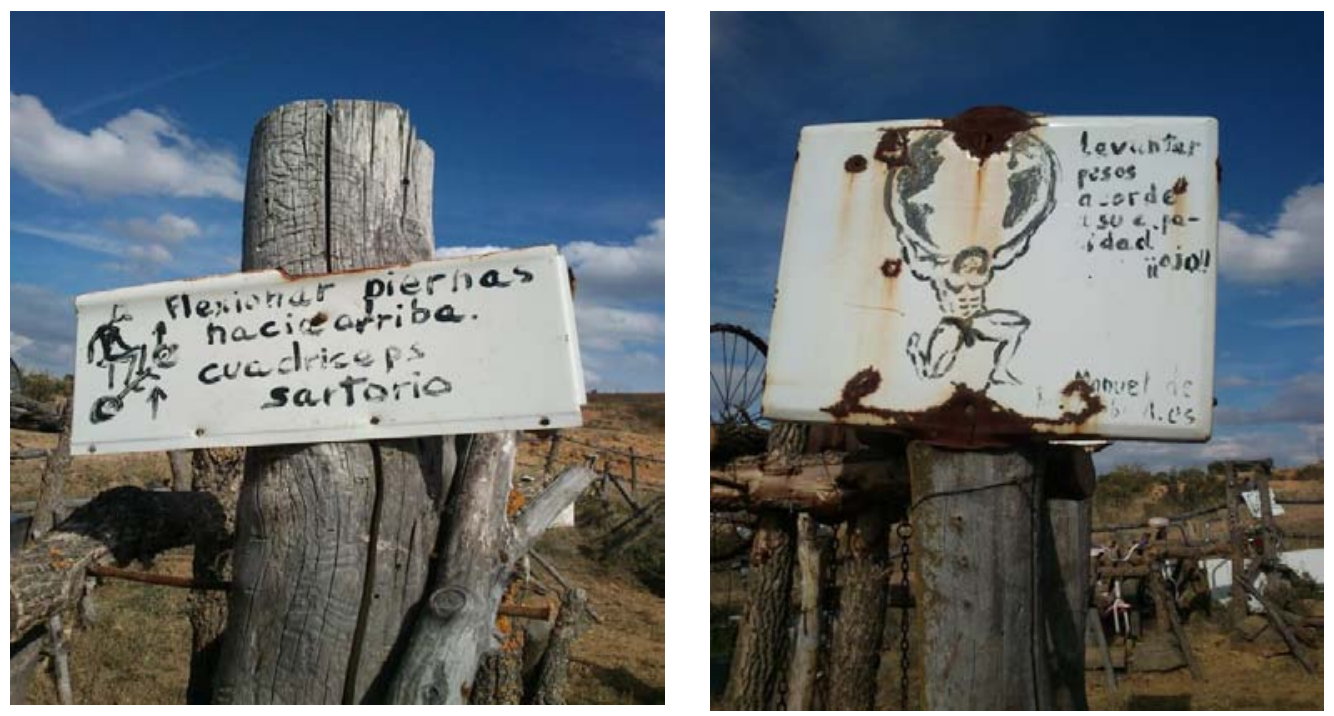

Foto 7. 1. Imagen izquierda: "Flexionar piernas hacia arriba. Cuádriceps. Sartorio. 2. En la imagen de la derecha se recomienda, "Levantar pesos acorde con su capacidad. ;Ojo!

Citius, Altius, Fortius Volumen 9 ne 1 Mayo, 2016. ISHN. 2340-9886.

http://dx.doi.org/10.15366/citius2016.9.1 
A todo lo anterior debemos de añadir los actos vandálicos, a pesar de que por fortuna no han sido demasiados, centrados sobretodo en el robo de materiales como el cobre o el hierro. El fuego también ha afectado a alguna parte del gimnasio, concretamente el que asoló parte de la maragatería en el año 2010 y que fue sofocado en los límites de la instalación.

Desde el punto de vista técnico, podemos encontrar todo tipo de aparatos, los propios de cualquier instalación moderna. Muchos de ellos han sido completados y mejorados en posteriores ampliaciones, con la intención de facilitar el desarrollo de diferentes grupos musculares con aparatos variados, como por ejemplo los existentes para el trabajo de pecho, por mencionar alguno. Podemos encontrar desde bicicletas estáticas o una noria, para el trabajo de la fuerza resistencia del tren inferior, hasta un aparato de esquí de fondo para mejorar la resistencia aeróbica, o máquina de remo con la misma finalidad, complejos aparatos del tipo multiestación donde trabajar diferentes grupos musculares, variados aparatos de press de banca para el trabajo de pecho, pesos libres y mancuernas de utilidad libre, múltiples aparatos de poleas para el trabajo de pecho y espalda, una pequeña instalación dotada de una cuerda para trepar y una escalera para el trabajo de brazos, aparatos para trabajar tríceps y bíceps, bancos para abdominales, prensas para el tren inferior o para el trabajo de gemelos, por mencionar algunos de ellos. Hemos comprobado como el funcionamiento de todos ellos es más que correcto y cumplen a la perfección su finalidad, nada sencillo a la vista de su complejidad.

En definitiva, nos encontramos ante algo que va más allá de una simple instalación deportivo- ecológica. Es una realidad difícilmente comparable a ninguna otra y que goza de una exclusividad propia directamente proporcional a la creatividad del autor. Es un modelo pedagógico a seguir, fruto de mucho trabajo y de una ilusión por lograr un espacio para todos mejor y cuyo balance es el resultado de una creación genuina que ayuda a quien la utiliza pero también al que la contempla.

A continuación presentamos diferentes aparatos propios de la instalación de Valdespino de Somoza y una equivalencia de lo que en la actualidad son los aparatos propios de cualquier instalación de este tipo. 


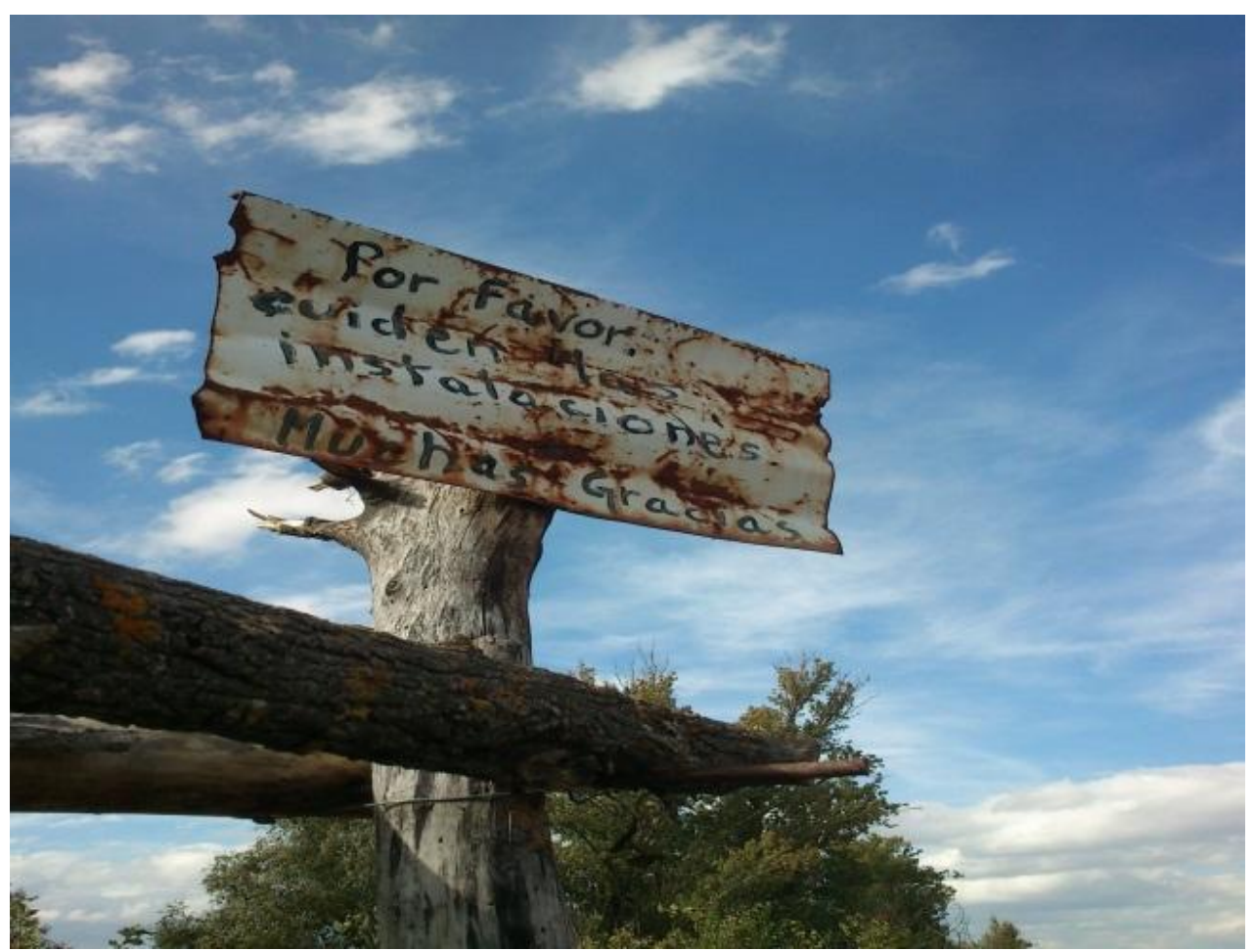

Foto 8. "Por favor cuiden la instalación. Muchas gracias"
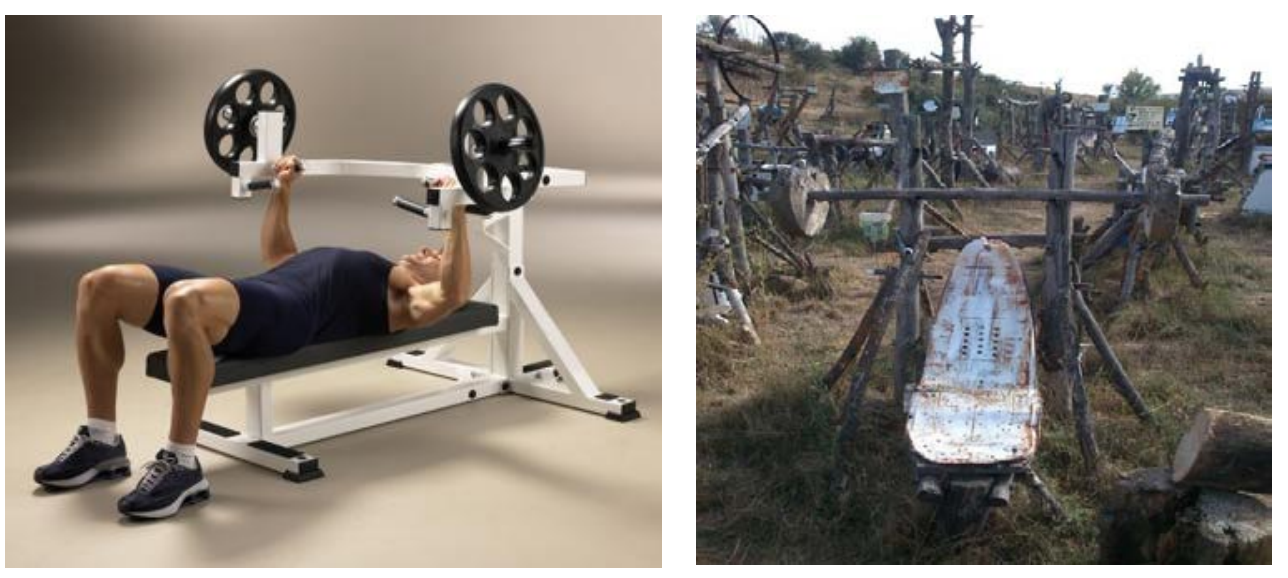

Foto 9. Press Banca

Citius, Altius, Fortius Volumen 9 ne 1 Mayo, 2016. ISHN. 2340-9886.

http://dx.doi.org/10.15366/eitius2016.9.1 


\section{Su autor, un Licenciado en Ciencias de la Actividad Física y del Deporte}

Importante es conocer al autor del gimnasio ecológico de Valdespino de Somoza, quien partiendo de una singular iniciativa, construye, repara y mantiene tan singular instalación. Su nombre es Manuel de Arriba Ares, natural de Valdespino a pesar de ser conocido por todos como "el argentino". Nació en esta localidad maragata hace 56 años, en la misma casa que habita en la actualidad. En 1978 viajó a Argentina para visitar a un familiar, y por circunstancias personales prolongó su estancia, permaneciendo durante veintiocho años en el país sudamericano. Allí transcurre, pues, buena parte de su vida. Se licenció en Educación Física, y ejerció la profesión docente. Persona de carácter extrovertido y sencillo de trato, casado y con dos hijos, muestra su cercanía y sencillez desplazándose a diario en bicicleta a la ciudad de Astorga, a ocho kilómetros de distancia, donde desarrolla su tarea profesional como responsable de las actividades deportivas extraescolares de un centro docente, su verdadera vocación. Además es entrenador de fútbol y de hockey.

La idea del gimnasio surge como pasatiempo ya que tras su vuelta de Argentina y mientras encontraba trabajo dedicaba buena parte de su tiempo a practicar deporte. En el paraje donde se dedicaba a estirar decidió ir montando su pequeño gimnasio como complemento a su preparación física. Sin embargo la finalidad del mismo está relacionada directamente con un hecho singular y cargado de historia desde el punto de vista de la biología ya que la madera protagonista y que conforma el material principal de la instalación es la del desaparecido negrillo. Al parecer la zona de Somoza reunía las condiciones ideales para este tipo de árbol antes de la enfermedad "mundial" que les afectó. En efecto, en Valdespino abundaba esta madera que fue utilizada como material principal estando ya enfermos y que acababan por secar y posteriormente morir. Siendo así y utilizando talas de apenas metro- metro y medio afectadas fueron utilizadas a modo homenaje ante su inminente desaparición. La idoneidad de esta codiciada madera se fundamenta en la gran dureza y ligereza frente a otras clases de madera más pesadas y menos resistentes y no obstante así lo refleja el autor en uno de los numerosos carteles informativos para los visitantes, ajustándose a la perfección para la creación de aparatos de fuerza en los que la fuerza, resistencia y durabilidad son fundamentales.

La finalidad del mismo ha sido la creación de un espacio abierto a todos, de carácter gratuito, y de uso libre, donde poder practicar deporte al aire libre, y manteniendo un absoluto respeto con el entorno. 

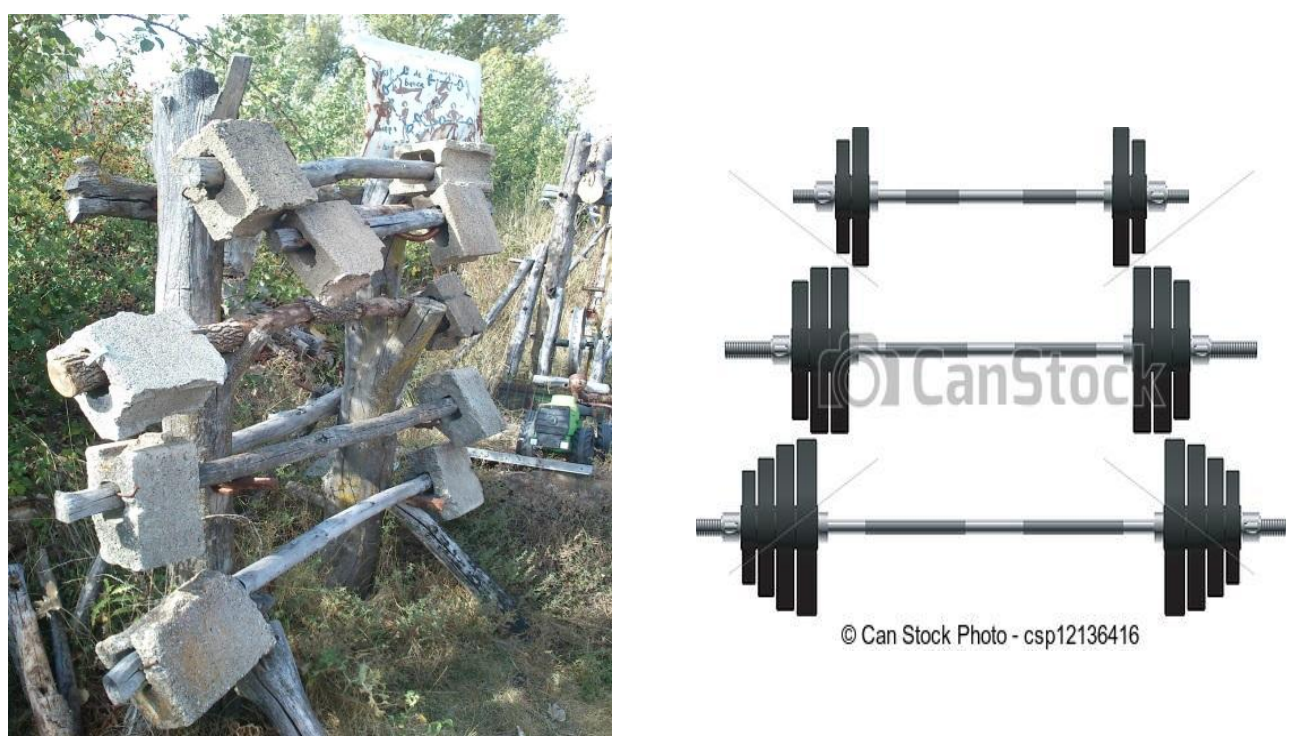

Foto 10. 1. Juego de pesas y mancuernas. 2. Imagen de barra de pesas y discos actual. Foto procedente de Can Stock Photo.
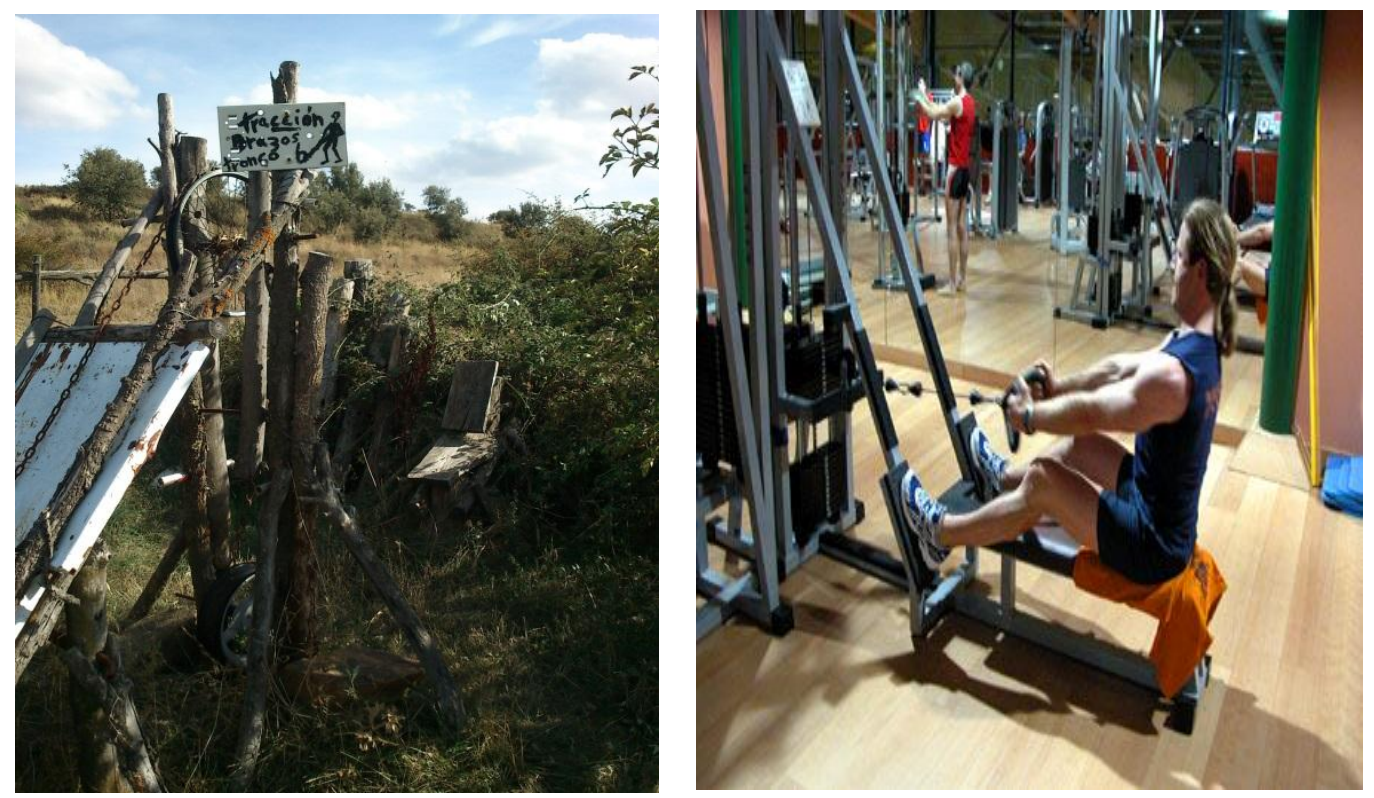

Foto 11. Máquina de remo vista desde la parte de detrás.

Citius, Altius, Fortius Volumen 9 ne 1 Mayo, 2016. ISHN. 2340-9886.

http://dx.doi.org/10.15366/eitius2016.9.1 
Existe mucho esfuerzo y dedicación detrás de cada aparato, no sólo para crearlo sino también para su mantenimiento. Cuando visitamos el gimnasio de Valdespino, percibimos que la ilusión por construirlo va unida al deseo del autor de que todo funcione correctamente y de acuerdo a los principios de uso de cada aparato.

\section{Bibliografía}

- Carta Olímpica. International Olympic Committe. www.olympic.org/ Consultado el 12/012016.

- Coubertin, P. 1888, La reforma social, Vol.8, serie 2, part. VI, pp. 249252.

- Coubertin, P. (1889). L’Éducation Anglaise en France. París. Libr. Hachette.

- Defrance, J. (1993). La signification culturelle de l'hébertisme. Etude de sociologie de la culture des années 20 et 30. Staps, 47-63.

- Gálvez Contreras, E. N. (2011). El método natural de George Hébert: una aproximación a la Educación Física en el Real Decreto de Educación Española. Recuperado el 23 de octubre de 2015. Revista Digital de Educación Física y Deportes, $\mathrm{n}^{\mathrm{o}}$ 160, septiembre de 2011. Buenos Aires. http://www.efdeportes.com/.

- Langlade, A., y Langlade, N. (1970). Teoría General de la Gimnasia: Génesis y panorama global de la evolución de la gimnasia. Buenos Aires: Stadium.

- Soares, C. L. (diciembre de 2002). Memórias da naturaleza: Georges Hébert e a educação do corpo. Recuperado el 22 de octubre de 2015, de Revista de Educación Física y Deportes:

http://www.efdeportes.com/efd55/hebert1.htm

- Villaret, S. (2003). L'influence du naturisme allemand sur l'éducation physique française tout au long du XIXe siècle. En J.-P. SaintMartin, Educations physiques nationales et exemplarités étrangères en France entre 1815 et 1914. Paris: L'Harmattan. 

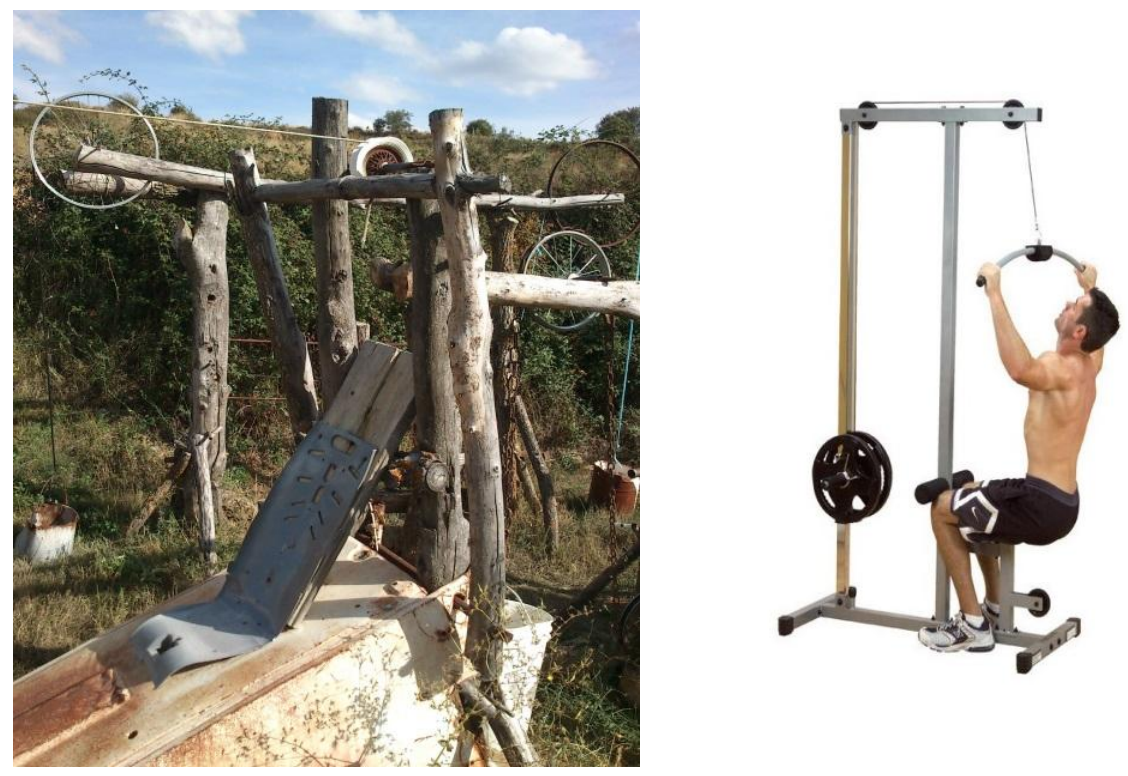

Foto 12. Máquina de poleas para pecho-hombros.
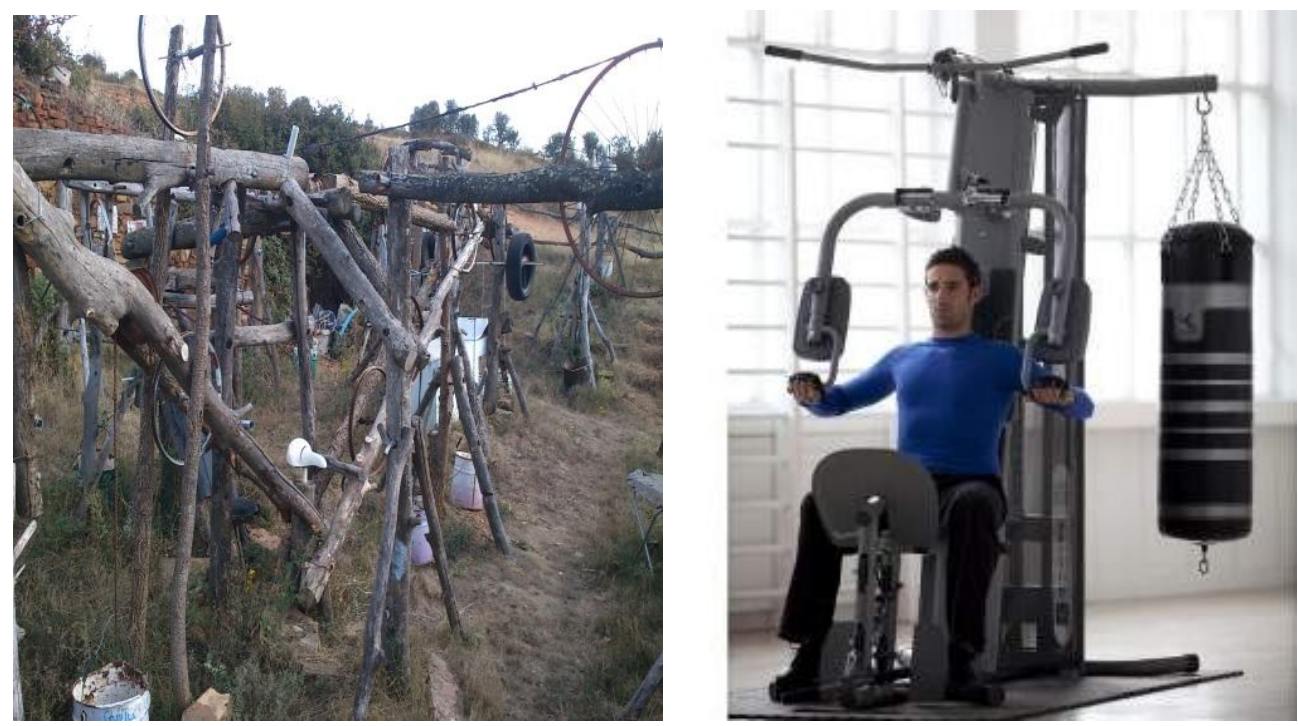

Foto 13. Multiestación de musculación.

Citius, Altius, Fortius Volumen 9 ne 1 Mayo, 2016. ISHN. 2340-9886.

http://dx.doi.org/10.15366/citius2016.9.1 


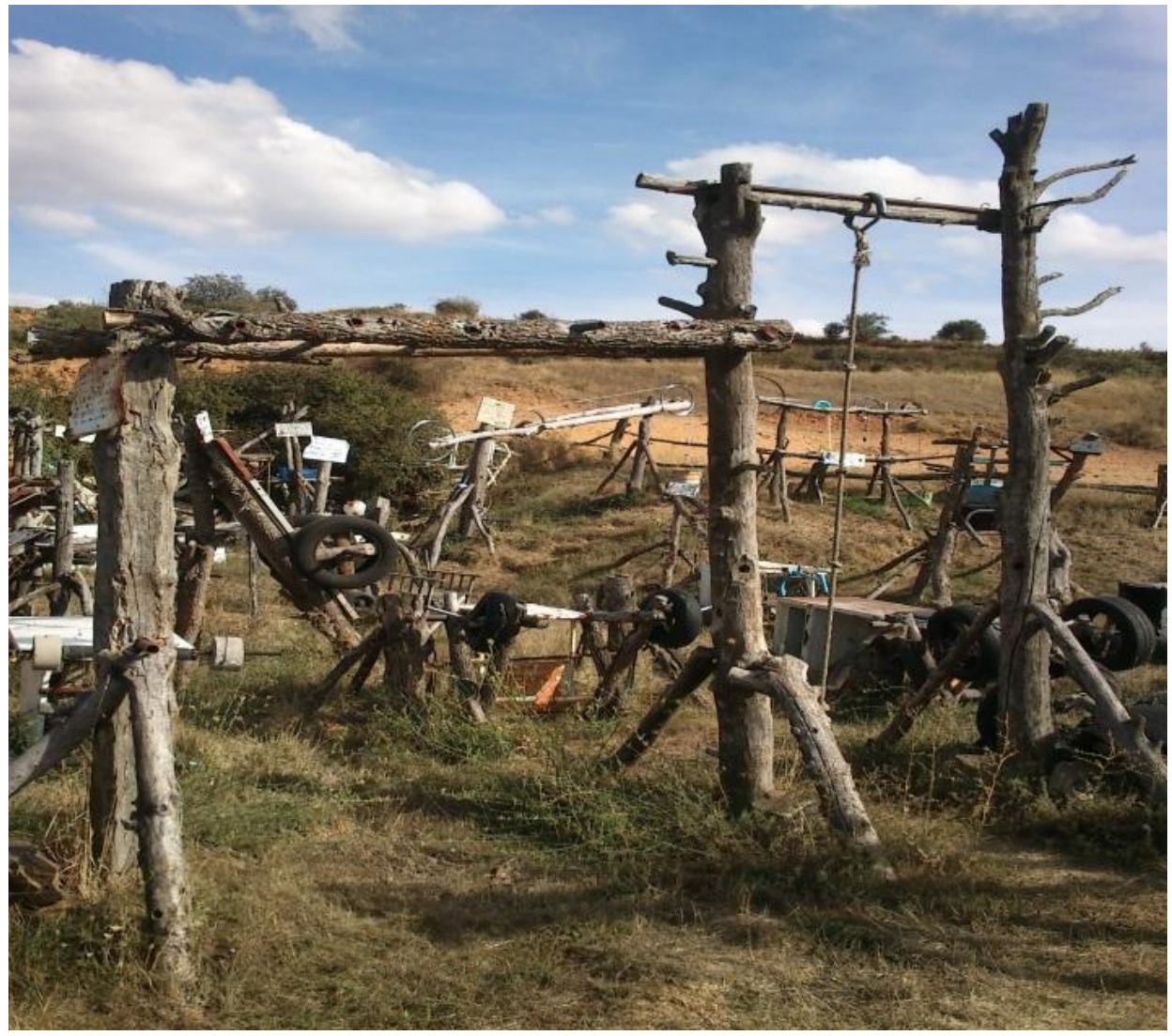

Foto 14. Instalación compuesta por escalera y cuerda para trepar.
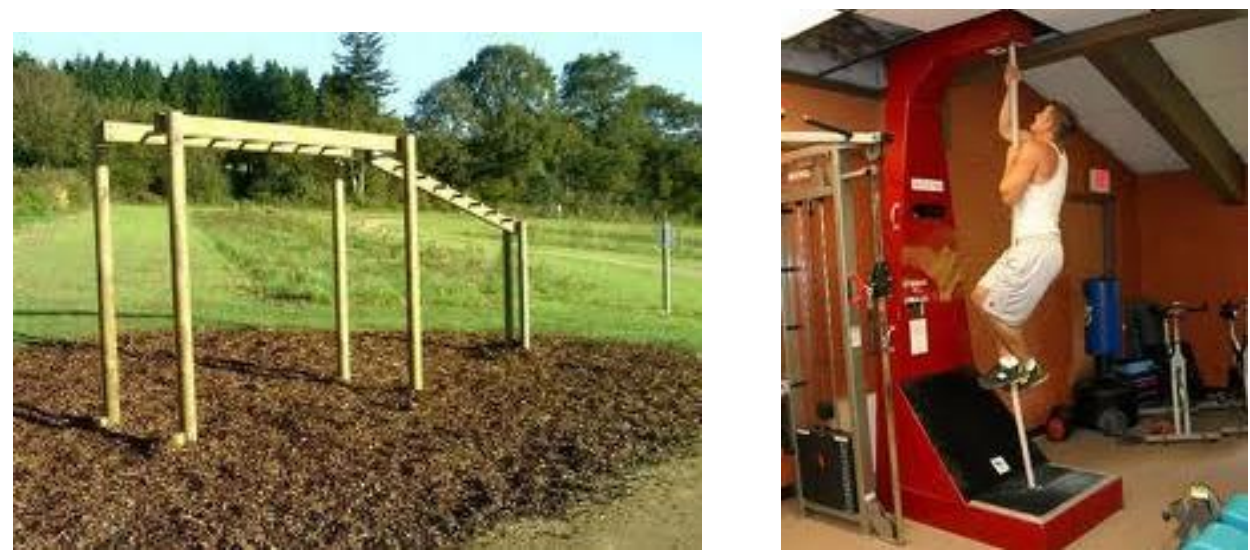

Foto 15. Instalaciones modernas de escalera y cuerda.

Citius, fltius, Fortius Volumen 9 ne 1 Mayo, 2016. ISHN. 2340-9886. http://dx.doi.org/10.15366/eitius2016.9.1 